\title{
RESISTÊNCIA INTELECTUAL AO NAZISMO NOS PERIÓDICOS DO EXÍLIO
}

ANDRADE, Patrícia Helena Baialuna de ${ }^{1}$

\begin{abstract}
RESUMO: As obras publicadas pelos escritores alemães no período em que se exilaram da Alemanha nazista compõem a chamada Literatura de Exílio, A este conjunto pertencem numerosas publicações de características bastante distintas, contudo, o engajamento é marca recorrente de muitas obras que procuraram denunciar a violência do nacional-socialismo. Paralelamente à publicação de obras literárias, muitos exilados envolveram-se na divulgação de revistas de literatura, arte e política, editadas em diversos países. Este artigo tem por objetivo apresentar as propostas e conteúdo de alguns desses periódicos, comentando uma amostra de textos e editoriais e apontando para a importância de tais revistas enquanto veículo de articulação de uma resistência intelectual ao nazismo.
\end{abstract}

PALAVRAS-CHAVE: Exílio, Periódicos, Resistência.

\section{INTELLECTUAL RESISTANCE TO NAZISM IN EXILE MAGAZINES}

\begin{abstract}
The LITERARY works published by German writers in the period in which they were exiled from Nazi Germany comprise the so-called Exile Literature. To this group belong numerous publications with quite different characteristics, however, engagement is a recurring mark of many works that sought to denounce the violence of the national -socialism. In parallel with the publication of literary works, many exiles became involved in the dissemination of literature, art and politics journals, published in several countries. This article aims to present the proposals and content of some of these journals, commenting on a sample of texts and editorials and pointing out the importance of such magazines as a vehicle for articulating an intellectual resistance to Nazism.
\end{abstract}

KEYWORDS: Exile, Magazines, Resistance.

\footnotetext{
${ }^{1}$ Mestre e doutora em Estudos Literários pela Unesp-Araraquara. Professora de literaturas lusófonas na Universidade Brigham Young (Provo-UT, EUA). patricia_andrade@ @yu.edu

Jangada | nr. 16, jun/dez, 2020 | ISSN 2317-4722 
Durante os anos em que vigorou o regime nacional-socialista na Alemanha, a maior parte dos principais intelectuais germânicos foi forçada a cruzar as fronteiras de sua pátria e lutar pela própria vida e por seus ideais em terras estrangeiras que lhes deram asilo. As obras literárias publicadas nesse período compõem o rico e heterogêneo que comumente se denomina Exilliteratur [literatura de exílio]. Os escritores alemães forçados ao desterro produziram não apenas obras literárias, mas também se envolveram, muitos deles, na publicação de revistas de literatura e política, como parte das atividades em que se engajavam nas comunidades de apoio mútuo que formaram em várias partes do mundo.

O objetivo deste artigo é apresentar o conteúdo, propostas e destacar a importância dos periódicos que os alemães publicaram em diversos países de asilo. Neste diversificado e interessante acervo, hoje compilado e disponível em uma coleção especialmente dedicada ao exílio na Biblioteca Nacional Alemã, pode-se observar os esforços pela articulação de uma resistência intelectual ao nazismo, além de propostas para a reconstrução do país e ideais de arte e literatura.

Apresentaremos a seguir algumas das revistas que foram publicadas em vários lugares do mundo, fruto da articulação de intelectuais que venciam a precariedade de recursos financeiros e muitas vezes técnicos para fomentar esses periódicos. Buscamos identificar as principais propostas colocadas pelas revistas selecionadas, discutir alguns dos textos que veicularam e, possivelmente, traçar-lhes um perfil enquanto meio de debate de ideias e divulgação de textos literários.

Ressalvamos que este trabalho é parte de uma pesquisa mais extensa, como resultado da qual já foram publicados artigos que analisam em maior extensão os periódicos Freies Deutschland / Alemania Libre, publicada no México (ANDRADE, 2015); Das Wort e Internationale Literatur, publicadas em Moscou (ANDRADE, 2017); e Aufbau, publicada em Nova Iorque (ANDRADE, 2016). Comentaremos brevemente, neste artigo, os periódicos Die Sammlung, Deutsche Blätter, Das Andere Deutschland / La Otra Alemania, Sozialistische Warte e Freie Kunst und Literatur.

Procuraremos mostrar, através da apresentação por amostragem do conteúdo desses periódicos, seu papel enquanto espaço de discussão e divulgação entre os intelectuais sujeitados ao exílio, estes sim figuras centrais no movimento de resistência ao nacional-socialismo. Através da atuação desses cidadãos - na maior parte alemães - fora das fronteiras de seu país 


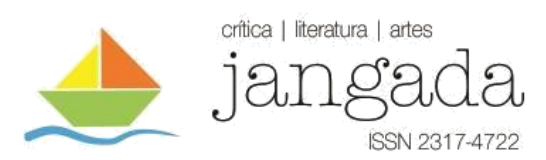

apontamos para a importância das revistas literárias enquanto veículo e palco de debates e defesa de ideias que alcançavam desde os âmbitos estético e ideológico da arte, propostas políticas e econômicas para a reconstrução da Alemanha após o tão esperado fím do governo nacional-socialista, e questões de ordem ética e social, como a culpabilidade dos cidadãos comuns alemães pela perpetração de atos violentos pelo Estado nazista.

A propósito da literatura engajada, eixo central de nossa leitura dos periódicos do exílio, recuperamos a reflexão de Benoît Denis (2002, p. 27) acerca de seu surgimento no século XX. Para o autor, o aparecimento e difusão dessa forma artística teria sido permitido - ou antes determinado - por três fatores. O primeiro deles foi a conquista de uma certa autonomia da arte com relação à sociedade na qual se inscreve. A literatura engajada só seria possível porque existe a possibilidade de uma arte pela arte. O segundo elemento listado por Denis é o surgimento da figura do intelectual na sociedade, que não é necessariamente um literato. Thomas Sowell define essa figura como pertencente a uma categoria ocupacional cujo produto final de seu trabalho são as ideias (SOWELL, 2011). Finalmente, o terceiro fator que, segundo Denis, impulsionou a literatura engajada no século passado foi a Revolução de Outubro de 1917, que fez com que muitos autores - não apenas russos - se envolvessem em questões políticas ao discuti-las em suas obras.

Ao atentarmos para o caráter político dos escritos no exílio, quer se tratem de textos literários ou de outros gêneros, partilhamos da concepção de Irving Howe (1998, p.4) segundo a qual se considera o político na literatura uma perspectiva de observação, e não uma rígida categoria de classificação. A classificação dos gêneros dos textos publicados nos periódicos do exílio é, definitivamente, uma questão à qual nos furtamos neste artigo; basta-nos recuperar, neste ponto, a postulação de Benoît Denis ao chamar de poligrafia a diversidade de gêneros utilizados pela literatura engajada:

[...] convém compreender a sua poligrafia como uma maneira para [o escritor engajado] de variar as suas intervenções, modulando-as pelos recursos específicos que lhe oferecem os diferentes gêneros que pratica; cada um deles constitui uma faceta de sua produção, uma maneira distinta e particular de colocar o (ou os) mesmo problema, tratando-o segundo aproximações diferentes que, em definitivo, procuram se completar uma com a outra. (DENIS, 2002, p. 82) 


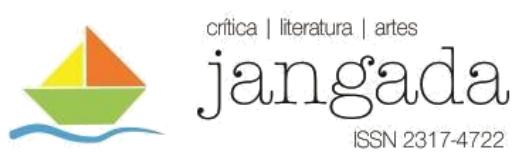

Ao analisarmos brevemente a proposta e possíveis diálogos ou repercussões de revistas do exílio alemão, como Die Sammlung, Deutsche Blätter, Freie Kunst und Literatur, entre outras, fundamentaremos nossos comentários a partir de textos de apresentação ou editoriais desses periódicos, além de outros textos apresentados. Procuraremos apontar suas especificidades e, também, suas possíveis convergências com as propostas das demais revistas.

\section{DIE SAMMLUNG}

Publicada por Klaus Mann com a editora holandesa Querido Verlag, Die Sammlung, assim como outros periódicos, contou com a colaboração de renomados escritores alemães, tais como Alfred Döblin, Stefan Zweig, Bertold Brecht, Johannes Becher, entre muitos outros. Entre setembro de 1933 e agosto de 1935, a revista mostrou ser mais que um caderno literário, tratando também da premente questão política que agitava os círculos intelectuais da época. Embora contando com o auxílio financeiro de Annemarie Schwarzenbach e não recebendo Klaus Mann honorários por seu trabalho, as dificuldades financeiras e o minguante número de assinantes puseram fim às edições de Die Sammlung.

O texto de apresentação da revista estabelece seus objetivos: servir à literatura, o que significa qualquer assunto elevado que não pertença a um único povo, mas a todos os povos da terra ("jener hohen Angelegenheit, die nicht nur ein Volk betrifft, sondern alle Völker der Erde”). Coloca-se, portanto, desde o primeiro parágrafo a visão de universalidade da arte e do pertencimento a ela de qualquer assunto elevado. Em seguida, o editor Klaus Mann comenta e critica - o engano (Verirrung) de um povo que insulta "seu melhor", cuja literatura é violada e tem que deixar o país. Segundo o autor, a verdadeira literatura alemã, que se encontra nessa situação, não pode se calar diante da degradação de seu povo, e o espírito de oposição chama à luta, apoiado pelos grandes nomes que figuram nas páginas do periódico apresentado. $\mathrm{O}$ elemento político é assim justificado:

Uma revista literária não é política; a crônica dos acontecimentos diários, sua análise ou a previsão do porvir não constituem seu conteúdo. Apesar disso, ela terá hoje uma missão política. Quem fizer o esforço de seguir os volumes de nossa revista não deve ter dúvidas de onde nos situamos nós, editores, ou 


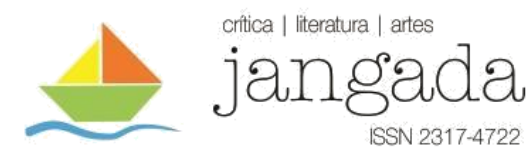

nossos colaboradores. Desde o início estará claro onde depositamos nosso ódio e nossa esperança. (DIE SAMMLUNG, ano 1, número 1). ${ }^{2}$

Embora distinga o componente literário do componente político em um periódico, o editor propõe não limitar os debates de Die Sammlung ao político, mas, abrangendo o campo artístico, deixar bastante claro a seus leitores o posicionamento da revista e de seus colaboradores. E esse posicionamento é claro: a crítica ao fascismo que, em terras alemãs, resultava em perseguição aos escritores e restrição da arte pela censura, além da repressão generalizada e instauração de um regime de medo e silêncio entre a população, que devia ser combatido pelas vozes da "verdadeira literatura alemã", estas que nunca deviam se calar. A própria palavra "oposição" mostra o intuito de articular os colaboradores da revista e seus leitores em um movimento de resistência ao nacional-socialismo a partir das discussões presentes nas páginas da revista.

\section{DEUTSCHE BLÄTTER}

A intenção política é assumida de forma mais enfática pelos editores da revista Deutsche Blätter, publicada por Udo Rukser e Albert Theile em Santiago do Chile, entre janeiro de 1943 e dezembro de 1946. Ao apresentarem o periódico com o texto intitulado "O que nós queremos"3, os editores classificam-no como "uma revista política" ${ }^{\text {, }}$, embora não se alinhe a nenhum partido específico, que busca "não uma estatização do homem, mas uma humanização do Estado"5, não uma Europa alemã, mas uma Alemanha europeia. Semelhantemente a outros periódicos, este também menciona a vergonha pelo que vinha sendo perpetrado pelos "compatriotas" alemães, e a necessidade de não ficarem aparte dos acontecimentos; calar-se não era admissível. Outra semelhança é a limitação de recursos, neste caso verbalmente mencionada na apresentação da revista. Ainda assim, os editores lutavam por mantê-la

\footnotetext{
${ }^{2}$ Eine literarische Zeitschrift ist keine politische; die Chronik der Tagesereignisse, ihre Analyse oder die Voraussage der kommenden macht ihren Inhalt nicht aus. Trotzdem wird sie heute eine politische Sendung haben. Ihre Stellung muss eine eindeutige sein. Wer sich die Mühe machen wird, die Hefte unserer Zeitschrift zu verfolgen, soll nicht zweifeln dürfen, wo wir, die Herausgeber, und wo unsere Mitarbeiter stehen. Von Anfang an wird es klar sein, wo wir hassen und wo wir hoffen lieben zu dürfen.

3 "Was wir wollen".

4 "eine politische Zeitschrift".

5 "keine Verstaalichung des Menschen, sondern eine Vermenschlichung des Staates".
}

Jangada | nr. 16, jun/dez, 2020 | ISSN 2317-4722

11| Pág in a 


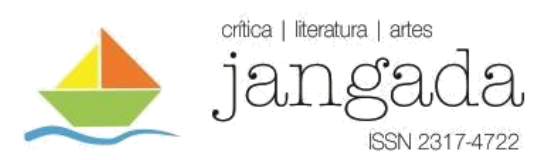

independente. $\mathrm{O}$ desejo de participar e contribuir com a resistência é expresso da seguinte maneira: "Como alemães, não desejamos ficar à parte enquanto nossos amigos buscam a liberdade de direito. [...]“6 (DEUTSCHE BLÄTTER, Caderno 1, 1943).

Outras ideias presentes nas propostas da revista eram a de construir para as futuras gerações, e de contribuir para uma nova ordenação da Alemanha e da Europa. Essa missão é colocada também no texto de apresentação do segundo ano de existência da revista, "Ao ano novo"” (DEUTSCHE BLÄTTER, Caderno 1, 1944): novamente os editores, dirigindo-se aos leitores, declaram não ser sua função empunhar a espada; outros poderiam fazê-lo melhor. Sua tarefa, enquanto intelectuais, seria a de

Auxiliar na superação deste tempo de sofrimentos, colaborar na reformulação após esta guerra, na medida em que isso é possível a tão modestas forças; e participar da preparação desta reformulação. (DEUTSCHE BLÄTTER, Caderno 1, 1944). ${ }^{8}$

A missão do intelectual ungido, tal como conceituado por Thomas Sowell (2011), é aqui reiterada: a reordenação social após o esperado fim da guerra e o olhar para o futuro eram prerrogativas destes que publicavam na revista. Embora se declarassem amistosamente apoiados pelos americanos, os editores não deixaram de lembrar, na abertura das edições de 1944, as dificuldades da vida no exílio.

Um importante colaborador da revista foi Thomas Mann, que no sétimo caderno de 1944 trouxe à pauta, com o texto "Destino e dever"9 , vários assuntos recorrentes às páginas dos periódicos do exílio, incrementados pela autoridade que o nome do autor suscitava. Mann traz ao debate a questão da culpa pelo nazismo, questionando em que medida poder-se-ia culpar o povo alemão em geral pela barbárie nacional-socialista; cita o sentimento de vergonha dos alemães exilados ao verem seus compatriotas perpetrando tão graves crimes; considera o nazismo uma variação do fascismo e, desse modo, desconfigura-o como especificidade alemã.

\footnotetext{
6 "Wir wollten als Deutsche nicht abseits stehen, während unsere Freunde nach einen gerechten Frieden suchen ".

7 "Zum neuen Jahre".

8 „,mitzuhelfen an der Überwindung dieser Leidenszeit, mitzuwirken an der Neu-Gestaltung nach diesem Kriege, soweit dies bei so bescheidenen Kräften möglich ist; und diese Neugestaltung geistig mit vorzubereiten ".

9 "Schicksal und Aufgabe".
}

Jangada | nr. 16, jun/dez, 2020 | ISSN 2317-4722

12 | P á g in a 
Para Mann, o fascismo, movimento oposto ao humanismo racionalista, era uma doença do tempo em que viviam, da qual nenhum povo estava livre. E a missão dos intelectuais entre os quais ele se coloca é formulada nos seguintes termos:

Nosso destino é ter que conduzir a luta contra nosso próprio país e suas coisas, por cuja depravação somos invadidos; contra o país cuja língua é a matéria espiritual com a qual trabalhamos; o país em cuja cultura crescemos, e cuja paisagem e atmosfera são também nossas montanhas naturais. (MANN, 1944). ${ }^{10}$

A acuidade da visão de Thomas Mann sobre a situação dos exilados traz em novas cores essa missão que, em outros textos, adquire tons mais heroicos: o triste destino desses homens e mulheres era lutar contra seu próprio país; por ele, mas contra ele, a despeito de quão profundamente estivessem suas paisagens, sua língua e cultura entranhados em cada um daqueles cidadãos desterrados. O espírito combativo com que essa missão foi frequentemente postulada tira de relevo a dura realidade dos fatos: os exilados tinham por dever lutar contra o que havia sido feito de seu solo, de suas origens, incertos do que restaria sob os escombros deixados pela destruição da guerra e do massacre nazista sobre o espírito humano. Sobre esses escombros precisariam reconstruir seu país, e para isso lá estariam os intelectuais à disposição e a serviço da "verdadeira" Alemanha.

10 “[...] unser Schicksal ist es, den Kampf gegen unser eigenes Land und seine Sache, von deren Verworfenheit wir durchdrungen sind, führen zu müssen, - gegen das Land, dessen Sprache der geistige Stoff ist, darin wir wirken, das land, in dessen Kultur wir wurzeln, dessen tradition wir verwalten, und dessen Landschaft und Lebensluft auch unsere natürliche Berge wäre”. 


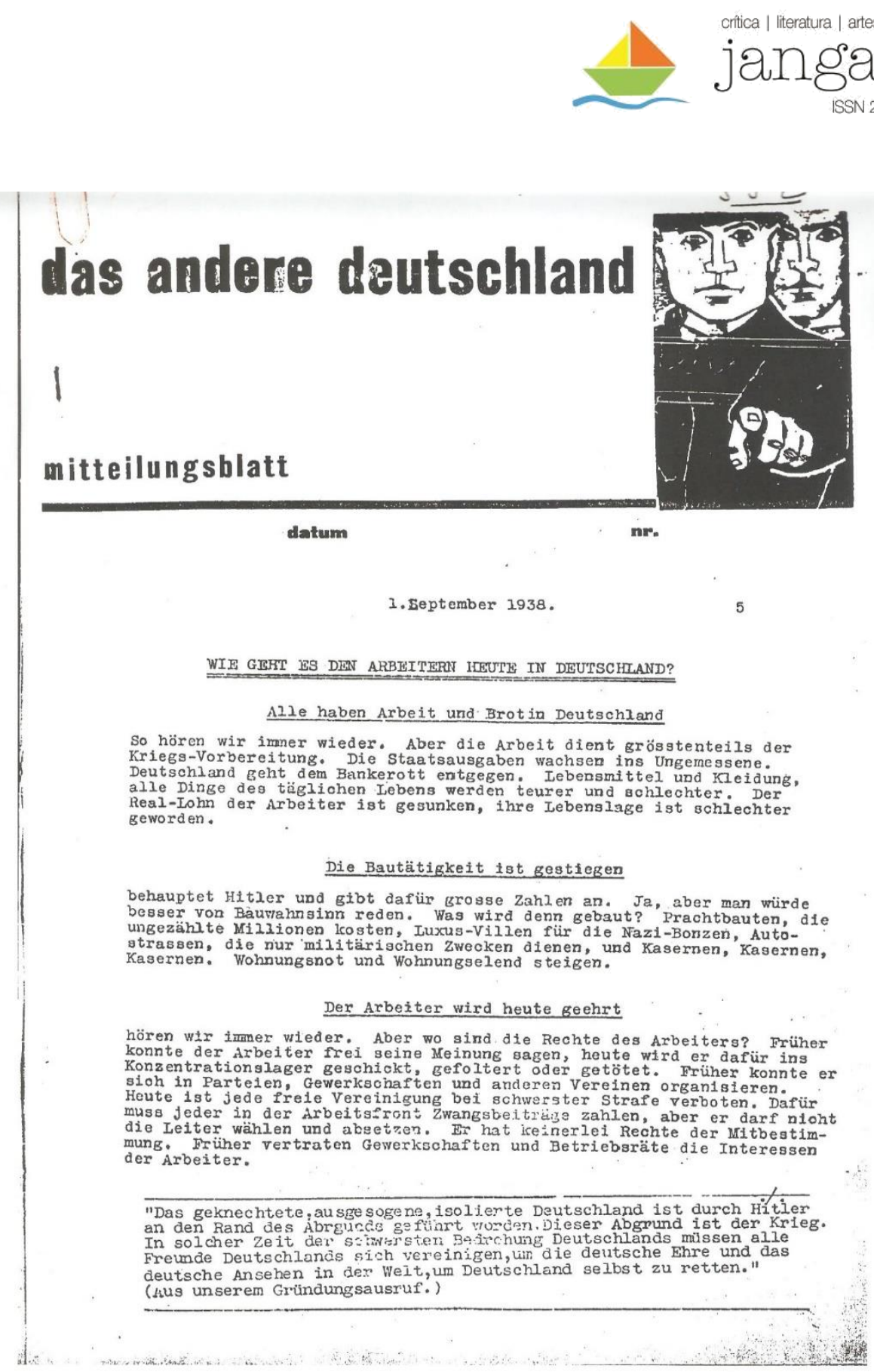

FIGURA 1 - DAS ANDERE DEUTSCHLAND, NÚMERO 5, 1938, CAPA Fonte: Exilarchiv da Biblioteca Nacional Alemã (DNB) em Frankfurt/Meno.

\section{DAS ANDERE DEUTSCHLAND/LA OTRA ALEMANIA}

Outro periódico publicado na América do Sul foi Das andere deutschland / La otra Alemania, subintitulado "órgão dos alemães democráticos da América do Sul"11, sediada em Buenos Aires e que publicava boletins mensais escritos por vários alemães exilados na Argentina e também

${ }^{11}$ Organo de los alemanes democraticos de America del Sur.

Jangada | nr. 16, jun/dez, 2020 | ISSN 2317-4722 


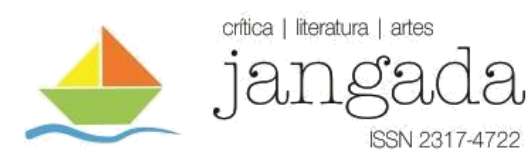

por colaboradores sul-americanos. Os escritos do periódico abordavam, basicamente, as mesmas preocupações dos demais periódicos analisados: as ações do nacional-socialismo, as condições de vida dos alemães sob aquele regime, a necessidade de unir forças contra o governo de Hitler, entre outros. O volume 5 de setembro de 1938, por exemplo, traz na primeira página a pergunta: "Como vão os trabalhadores na Alemanha?" 12, à qual são dadas várias respostas falaciosas - as respostas normalmente ouvidas do governo alemão, de que havia abundância de empregos, muitas obras sendo construídas, que os trabalhadores eram valorizados etc. A cada uma dessas respostas, porém, os autores da Das andere Deutschland contra- argumentam, mostrando a situação alemã através de um outro viés, e chegando às seguintes conclusões: que a situação do trabalhador alemão piorara; que vinha perdendo seus direitos (principalmente no que se referia à associação e sindicalização), assemelhando-se cada vez mais a um escravo; que, na guerra que se mostrava iminente, ainda caberia a esse trabalhador oferecer sua própria vida como combatente. Logo adiante outra coluna contabiliza os gastos astronômicos das últimas manobras militares encetadas por Hitler, reforçando que a economia que, segundo os nazistas, vinha beneficiando os trabalhadores, na verdade baseava-se em produção de artefatos bélicos.

Uma seção do periódico dedicava-se a noticiar as ações anti-nazismo que eram tomadas no continente americano, não apenas na Argentina, mas também nos Estados Unidos, Canadá, Chile, Peru, Brasil ${ }^{13}$, entre outros. Esta mesma seção noticiou, em novembro de 1938 (volume 7), a criação, nos Estados Unidos, da Schutzverband deutsch-amerikanische Schriftsteller $^{14}$, cuja missão seria a de unir os escritores, jornalistas e cientistas contra a infiltração nazista na América, além de proteger a "verdadeira cultura alemã", sob a presidência de Thomas Mann.

\footnotetext{
${ }^{12}$ Wie geht es den Arbeitern in Deutschland?

${ }^{13}$ As notícias do Brasil frequentemente faziam menção ao fechamento de escolas alemãs no sul do país, consequência da lei de nacionalização do ensino instituída no governo de Getúlio Vargas, e ocasionalmente à prisão e deportação de algum alemão acusado de disseminar ideias nazistas.

14 “Associação de proteção aos escritores teuto-americanos".
} 


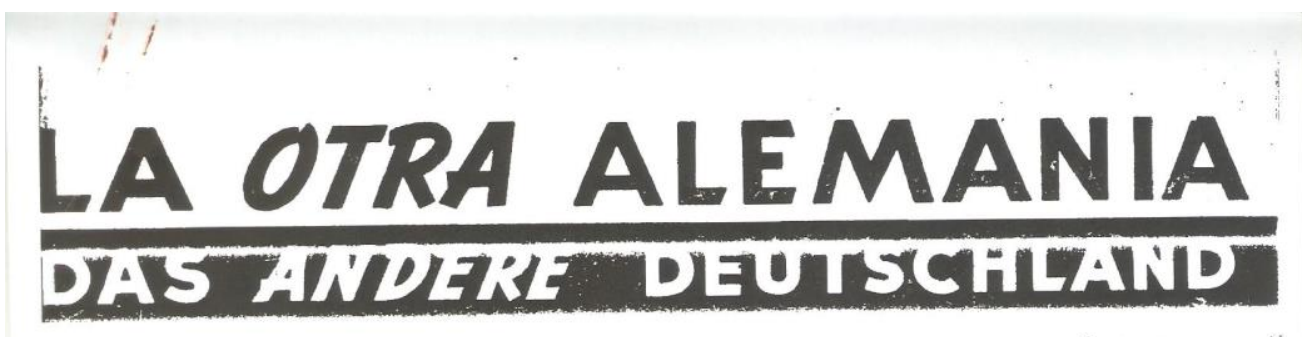

- IORgano de los alemanes dem ocraticos de america del suri FRIEDENS - SONDE RNUMMER AÑO VII No. 94 $M A Y O \quad 15$ DE 1945 $B \cup E N O S$ A I R E S $T \cup C \cup M A N 30$ $N$ U. T. $31-R E$ T I R O $\mathbf{T}$ - 7264 AUS DEM INHALT : José Venegas: Lo que no debemos olvidar

Sigfrido Ciccotti: La ocupación militar y la educación del pueblo alemán August Siemsen: Das Ende des alien und die Aufgabe des neuen Deutschland

Harold J. Laski: Der Friede, für den wir kämpfen

Hans Lehmann: Der internationale Wiederaufbau und Deutschland Hans Jahn: Dieses Geld

Erhart Löhnberg: Gestern und Morgen

Carl Döbbeling: Was soll nach Hitler kommen?

Curt Bestvater: Die Stunde des An deren Deutschland

Waldemar Ossowski: Die Knechtschaft hat ein Ende

Willi Karbaum: Macht nicht halt vor den Schlössern

Wili Keller: Der Kampf beginnt

Curt Fabian: V-Tag $\underset{\text { Frauen }}{\text { Christa Springmann: Aufgabe der }}$

\begin{tabular}{|c|c|c|}
\hline 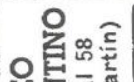 & FRANQUEO & PÄGADO \\
\hline 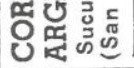 & CONCESION & No. 3096 \\
\hline
\end{tabular}

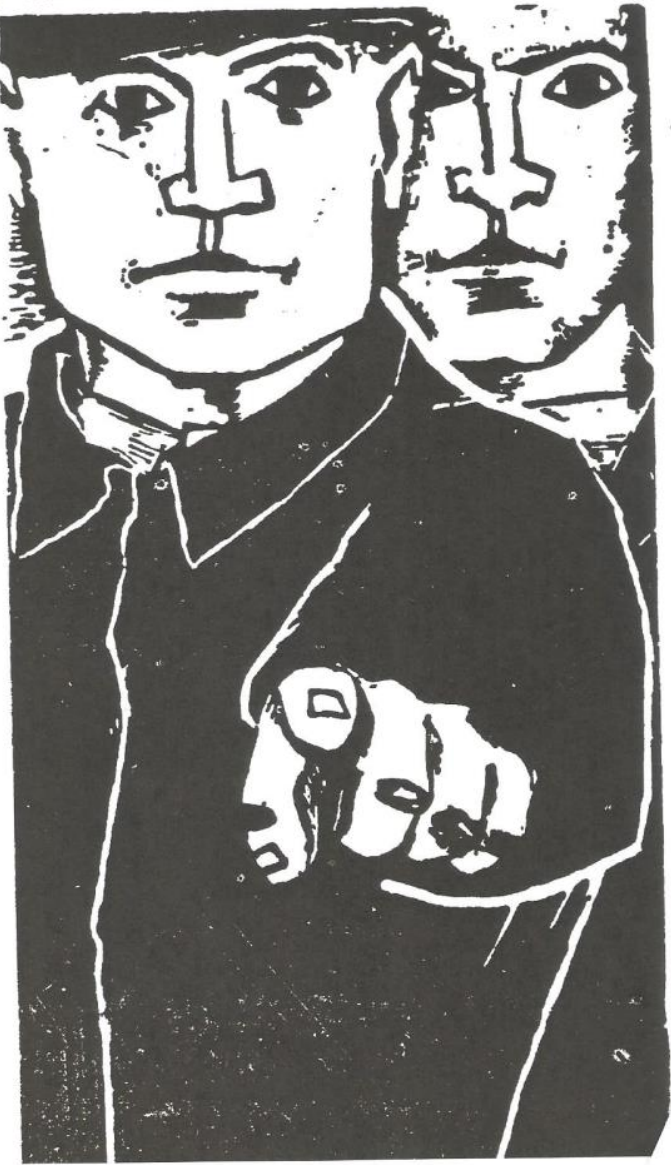

FIGURA 2 - DAS ANDERE DEUTSCHLAND, NÚMERO 94, 1945, CAPA Fonte: Exilarchiv da Biblioteca Nacional Alemã (DNB) em Frankfurt/Meno.

Ainda do primeiro volume mencionado, de setembro de 1938, citamos uma passagem emblemática da missão a si atribuída pelos fundadores de Das andere Deutschland: "Nesta época de tão grave ameaça a Alemanha, todos os seus amigos devem se unir para salvar a honra 


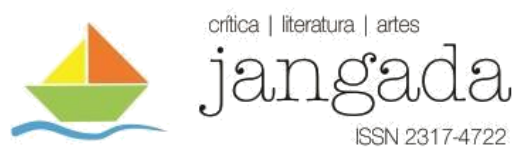

alemã, sua imagem para o mundo, a própria Alemanha."15 (DAS ANDERE DEUTSCHLAND, 1938, nr.5, p.1). Note-se que os termos utilizados são aqueles que sistematicamente se observam nas propostas das revistas do exílio: a necessidade de se unirem (sich vereinigen), que mostra o papel da revista como pretensa articuladora de um movimento de resistência a partir da intelectualidade, e o intuito de salvar a Alemanha (retten) das mãos dos nazistas, associando o intelectual envolvido nesse movimento ao papel de ungido (SOWELL, 2011), destinado a conduzir sua nação a um melhor futuro.

Uma especificidade de Das andere Deutschland era o incentivo à efetiva participação de seus leitores no periódico: no volume 6 de 1938, por exemplo, lemos o pedido da redação aos leitores para que lhes enviassem materiais como cartas vindas da Alemanha, recortes de jornais, notícias de outros países e outros que pudessem ser do escopo de interesse do periódico.

Como outras revistas, esta também publicou, em maio de 1945, um volume especial dedicado ao fim da Segunda Guerra (figura 2), espécie de edição comemorativa, de maior extensão em páginas e que celebrava o fim do nazismo, não deixando, contudo, de trazer à tona uma série de questões problemáticas que se apresentavam mediante essa nova fase da Alemanha. Com textos em espanhol e em alemão, a declaração inicial da revista, que apresenta o volume, vislumbra um futuro para os alemães, o qual eles deveriam buscar

en el trabajo, en la organización democratica y el progreso social dentro de una Europa democratica. Consideramos como nuestra primordial tarea, la de colaborar en la reconstrucción de la Europa devastada y de una Alemania pacífica y progresista que, una vez, ha poseído el respeto y la amistad del mundo. Asi, trataremos de tildar la vergüenza que Hitler trajo para Alemania. (DAS ANDERE DEUTSCHLAND, 1945, número 94).

Novamente nos deparamos com expressões-chave usadas pelos intelectuais em seus esforços de movimentação e resistência: a vergonha que o nacional-socialismo havia trazido sobre o cidadão alemão; e a incumbência de colaborar com a reconstrução de um país devastado, tendo por base o pacifismo e a democracia. Outros textos do mesmo volume também discutem as mudanças que deveriam ser operadas na sociedade alemã a partir daquele momento para uma completa reconstrução a partir das ruínas em que se encontrava. À literatura é cedido

\footnotetext{
${ }^{15}$ In solcher Zeit der schwersten Bedrohung Deutschlands müssen alle Freunde Deutschlands sich vereinigen, um die Deutsche Ehre und das Deutsche Ansehen in der Welt, um Deutschland selbst zu retten Nesta época de tão grave ameaça à Alemanha, todos os seus amigos devem se unir para salvar a honra alemã, sua imagem para o mundo, a própria Alemanha.
} 
um pequeno espaço - embora esse não seja o foco da revista - neste número: o poema "Esse dinheiro" "16, de Hans Jahn, lista em cinco estrofes e trinta versos os horrores e investimentos que haviam sido feitos com o dinheiro alemão em nome da guerra promovida pelos nazistas, e termina mostrando tudo que poderia ter sido feito com todo esse dinheiro pelo bem do povo, principalmente, evitando-se a fome, a doença e a destruição da própria guerra.

\section{SOZIALISTICHE WARTE}

Outra revista de caráter mais político que literário foi Sozialistische Warte, publicada em Paris pela Liga internacional de luta pelo socialismo ${ }^{17}$. Teve como editor Willi Eichler, e entre maio de 1934 e maio de 1940 teve como colaboradores Walter Auerbach, Kurt Hiller, Fritz Eberhard, entre outros.

O subtítulo da revista revela, em parte, seu propósito: "Páginas para um socialismo crítico e ativo" ${ }^{18}$, e a contracapa traz citações (de alguns anos antes) de líderes socialistas como Lenin, Trotski e Leonard Nelson. Não considerando o caso russo como uma vitória plena, a revista declara o intuito de servir à luta pelo socialismo, que até então vinha sendo perdida como seus próprios editores declaram no texto "Novos caminhos" ${ }^{19}$, de apresentação do primeiro volume do periódico. Outros ideais socialistas são reafirmados, como a necessidade de se deixar de lado as diferenças entre grupos e partidos pela instituição plena de um novo modo de organização social, a não separação entre as nações, a crítica à exploração organizada promovida pelo capitalismo, a valorização da associação entre os trabalhadores - enquanto o capitalismo apostava em seu isolamento e consequente enfraquecimento -, e a urgência de passarem da interpretação do mundo - já feita pelos filósofos - à ação transformadora.

Outro texto deste primeiro número da Sozialistische Warte, "Primeiro de maio"20, escrito por Walter Holz, alerta para a crescente supressão das manifestações dos trabalhadores. Observe-se que ainda em 1934, pouco mais de um ano após a tomada do poder por Hitler, o autor percebia e denunciava as "medidas fascistas" que se tornavam cada vez mais comuns com o fortalecimento da figura do Führer. O título do artigo de Holz diz respeito ao dia do trabalhador alemão, instituído pelo ministério da propaganda alemão e, segundo Holz, um claro

\footnotetext{
16 "Dieses Geld".

17 "Internationaler Sozialistischer Kampfbund".

18 "Blätter für kritisch-aktiven Sozialismus".

19 "Neue Wege".

20 "Der 1 Mai".
} 
truque de marketing, uma vez que o poder dos empresários só aumentava. De modo geral, as questões que ocupavam as páginas da Sozialistische Warte eram relacionadas à luta pela instituição do socialismo, à crítica ao capitalismo, à denúncia das más condições e da perda dos direitos dos trabalhadores alemães e outras medidas dos nazistas que prejudicavam aquela classe.

\section{SOZIALISTISCHE WARTE \\ Blätter für kritischaktiven Sozialismus

\begin{tabular}{lll}
\hline I. Jahrgang. I. Heft. & MAI 1834. \\
\hline
\end{tabular}

\section{INHALT :}

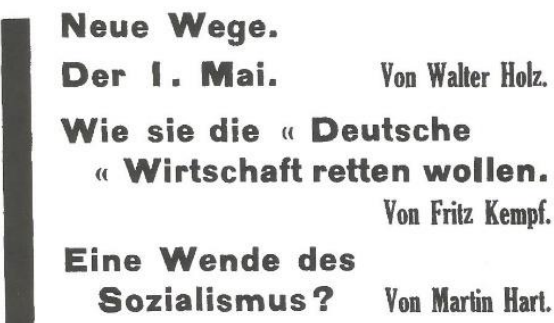

Wlo Innen « Waffen aus dep Faust quellen "I

Zeitnotizen :

Die Ethlk dep voelkisch yebundionen Produzenten und Volksyenessen. - Dle Rache des voelkischen Cewalthabers. - Die Rolle der rirche in Deutschland.

FIGURA 3 - SOZIALISTISCHE WARTE, CADERNO 1, 1934, CAPA

Fonte: Exilarchiv da Biblioteca Nacional Alemã (DNB) em Frankfurt/Meno.

\section{FREIE KUNST UND LITERATUR}

Interesse diverso tinha a revista Freie Kunst und Literatur, publicada em Paris a partir de setembro de 1938. Tendo como editor Paul Westheim, o periódico se destinava principalmente 


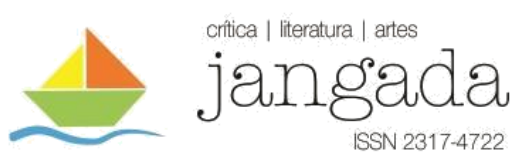

à comunicação das atividades de quatro organizações, a saber: a Schutzverband deutscher Schriftsteller, a Freie Künstlerbund, a Freie Deutsche Hochschule/Volkshochschule, sediadas em Paris, e a Oskar-Kokoschka-Bund, sediada em Praga. Para os membros dessas associações, inclusive, a revista - que era mensal - era gratuita. Seus propósitos são apresentados na segunda página do primeiro número, após uma gravura feita por Eugen Spiro de Thomas Mann proferindo um discurso. O cabeçalho da página traz as seguintes palavras:

O que nós queremos:

ensinar.

Ensinar sobre o trabalho cultural que exercemos.

Ensinar sobre a destruição cultural através do terror nazista. ${ }^{21}$

Sua finalidade era, portanto, primordialmente educativa: divulgar aos membros das ligas e a outros leitores o trabalho artístico de seus membros, suas ações em defesa da cultura alemã e alertar quanto aos prejuízos que a censura e perseguição nazistas vinham trazendo às manifestações culturais germânicas de modo geral. De título emblemático, o texto que segue essa declaração é "Unidos pela defesa da cultura" ${ }^{22}$, um relato do congresso de escritores realizado pouco tempo antes em Paris com esse ideal, citando uma fala do secretário do evento, Louis Aragon, e comentando o aparato de censura estruturado na Alemanha pelo Ministério da Propaganda, a Gestapo e o Reichskulturkammer. As páginas seguintes desse número introdutório da revista trazem uma série de notas e comentários relativos à arte alemã, como uma homenagem ao falecido Stefan George, a divulgação da exposição “Arte alemã do século XX" ${ }^{23}$, realizada em Londres, a resenha de um livro sobre a obra de Bizet, e esclarecimentos sobre a atuação de cada uma das quatro ligas ou instituições responsáveis pelo periódico. São também comentados recentes eventos teatrais promovidos pelo Reich, avaliados pelos editores como grandes produções de pouquíssimo valor artístico; divulga-se um concurso literário promovido pela agência londrina James B. Pinker \& Son, e outras atividades relacionadas.

Quanto às posições defendidas pela edição da revista, podemos apenas inferir a partir de trechos transcritos de falas de artistas como H.G.Wells, comentando a tarefa do escritor em

\footnotetext{
21 ,Was wir wollen:

Unterrichten:

Unterrichten über die Kulturarbeit die wir leisten,

Unterrichten über die Kulturvernichtung durch NS-Terror.

22 "Verbunden in der Verteidigung der Kultur".

23 "20th Century German Art Arte alemã do século XX".
} 


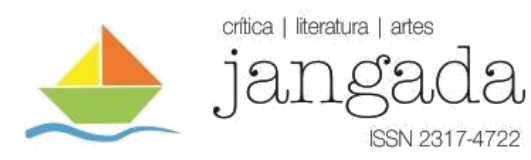

seu tempo: "O escritor não é um político, mas fatos e ideias políticas podem ser material adequado para sua arte." ${ }^{24}$ (FREIE KUNST UND LITERATUR, n. 1, p. 7). O autor defende, antes de tudo, uma arte livre, desincumbida de obrigações políticas, embora com a possibilidade de explorar questões de cunho político de modo bem-sucedido. A concepção apresentada por Wells e difundida pela revista é, portanto, bastante diferente daquela que vimos ser debatida em outras revistas, especialmente por Lukács ao defender o realismo na década de 1930. A posição diversa das ligas, dos editores ou, se assim quisermos dizer, da Freie Kunst und Literatur já se mostrava em seu título, e os excertos e declarações encontrados em suas páginas apenas vêm corroborar essa defesa.

\section{CONSIDERAÇÕES FINAIS}

Ao observarmos a partir de uma perspectiva mais ampla a atuação e alcance desses periódicos, recapitulamos as principais ideias presentes e defendidas em seus textos, o intuito expresso por seus editores e o espaço dedicado às discussões de caráter estético, político, social e até mesmo ético. Partimos da consideração de que

toda sociedade tem os seus detentores do poder ideológico, cuja função muda de sociedade para sociedade, de época para época, cambiantes também as relações, ora de contraposição, ora de aliança, que eles mantêm com os demais poderes. (BOBBIO, 1997, p. 11)

No caso de que tratamos, a relação dos intelectuais alemães exilados com o poder instituído é de contraposição, relação claramente expressa pelo conteúdo das revistas que procuramos apresentar, respeitadas suas particularidades.

Um dos pontos fundamentais que caracterizam essas publicações como tentativa de articulação de um movimento de oposição ao nazismo é a comunicação - ou mesmo colaboração - entre os círculos responsáveis pelas diferentes revistas, em diversas partes do mundo. Frequentemente nos deparamos com os mesmos nomes na lista de colaboradores de

\footnotetext{
${ }^{24}$ „Der Schriftsteller ist kein Politiker, aber politische Tatsachen und politische Ideen können für seine Kunst ein geeigneter Stoff sein “.
} 


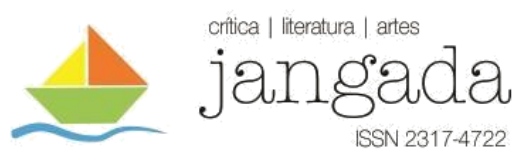

mais de um periódico, e os esforços se davam especialmente no sentido de auxiliar na difusão das ideias veiculadas. Como vimos, o engajamento só se dá através do alcance das massas, e, para isso, era necessária a divulgação dessas ideias e sua transformação em ações de resistência que seriam de incumbência do povo. Esse seria o objetivo último dos idealizadores do Volksfront, os quais acreditavam no poder do povo enquanto agente de mudanças sociais, e, nesse sentido, a dificuldade de difusão e distribuição das revistas era um grande empecilho.

Em geral, os exilados envolvidos nesses projetos eram unânimes em defender que o escritor não podia limitar-se ao silêncio diante das catástrofes a que assistiam ou das quais tomavam conhecimento, o que reafirma a função social do escritor - e, por que não, do intelectual, que se considerava responsável, enquanto situado em uma posição privilegiada de compreensão dos fenômenos sociais, por apontar os caminhos que levariam sua nação a um futuro de paz e progresso. Entretanto, a necessidade de incitar a população garantia que os intelectuais - embora comumente atribuam-se uma posição superior na sociedade - não pudessem desprezar as massas isolando-se na torre de marfim de seus círculos, e o maior ou menor sucesso na difusão das ideias dependia em grande parte da capacidade dos editores de dialogar com outras instâncias sociais, como os trabalhadores. Numerosos foram os textos publicados nos periódicos do exílio que apresentaram análises da situação econômica e política, não só da Alemanha, mas também da Europa, e propuseram medidas para a transformação alemã após o fim do governo nacional-socialista, do qual quase todos esperançosamente previam a iminente derrocada. Essa atuação vem ao encontro do que Bobbio considera como a atitude ideal de um intelectual, como aquele que tem "uma forte vontade de participar das lutas políticas e sociais de seu tempo" (BOBBIO, 1997, p.79).

Enquanto veículos de divulgação e crítica literária, serviram a valiosos debates e, acima de tudo, à colaboração e valorização dos artistas que, destituídos dos próprios meios de sobrevivência no exílio, maiores dificuldades encontravam para publicar suas obras. Foram publicados incontáveis poemas, capítulos de romances, contos, resenhas de obras literárias, teatrais e cinematográficas, e tudo o mais que pudesse interessar aos defensores da cultura que viam a arte alemã dispersar-se pelo mundo enquanto dentro do território alemão o solo só era fecundo para uma arte doutrinária, de menor valor, que enaltecia o "espírito alemão" e ignorava o despertar da consciência que a verdadeira arte promove.

Consideradas as particularidades de cada periódico, as quais procuramos inclusive apontar, algumas ideias puderam ser sistematicamente identificadas nas páginas que comentamos desses veículos. Em que pese dessem alguns maior relevo às questões artísticas, Jangada | nr. 16, jun/dez, 2020 | ISSN 2317-4722 


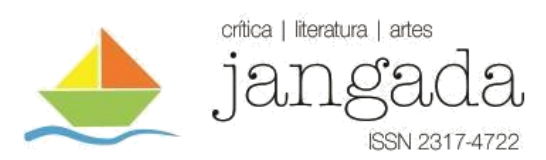

outros à política, outros à sociedade e outros a um pouco de cada uma dessas instâncias, a defesa da liberdade é uma das principais recorrências dessas revistas: liberdade para a arte - em contraposição à arte nazista ou até mesmo à arte ideologicamente formatada preconizada pelo realismo socialista; liberdade para o povo contra a opressão e a violência do nacionalsocialismo. Ora defendendo a democracia no capitalismo, ora defendendo o socialismo, o objetivo comum era unir forças, inclusive através de interferências de outros países, para salvar a Alemanha do governo de Hitler e da destruição da guerra. Fosse em favor do realismo socialista ou defendendo a experimentação de novas formas artísticas, os artistas e intelectuais se uniram com o propósito de libertar a Alemanha e, para isso, viam como protagonista das transformações sociais desejadas o povo. Através da mobilização de um Volksfront a tirania nazista seria minada de dentro de sua própria estrutura; aos intelectuais, portanto, caberia conclamar o povo à ação, através de seus manifestos e, também, da capacidade transformadora da arte.

\section{REFERÊNCIAS BIBLIOGRÁFICAS}

ABUSCH. Alexander. Vorwort. In: Freies Deutschland: México, 1941-1946. Bibliographie einer Zeitschrift. Berlin e Weimar: Aufbau-Verlag, 1975, p.5-21.

ANDRADE, Patricia Helena Baialuna de. Revistas de literatura e política: estandartes dos intelectuais antinazistas exilados. In: Revista Tempos Históricos, v. 19, p. 228-252, 2015.

A cultura judaica em um periódico do exílio alemão: o caso da revista Aufbau. In:

ContraCorrente: Revista de Estudos Literários, v. 9, p. 1-13, 2016.

. A literatura de exílio alemã nas páginas da revista Das Wort: o realismo em questão. Miscelânea (Assis. Online), v. 20, p. 325-342, 2017.

DAS ANDERE DEUTSCHLAND. Buenos Aires, Número 5, 1. Setembro de 1938.

BOBBIO, Norberto. Os intelectuais e o poder. Dúvidas e opções dos homens de cultura na sociedade contemporânea. Tradução de Marco Aurélio Nogueira. SP: Editora da Universidade Estadual Paulista, 1997.

HOWE, Irving. A política e o romance. São Paulo: Editora perspectiva, 1998.

FREIE KUNST UND LITERATUR. Paris, Número 1, Setembro de 1938.

DENIS, Benoît. Literatura e engajamento: de Pascal a Sartre. Tradução Luiz Dagobert de Aguirra Roncari. Bauru, SP: EDUSC, 2002. 
DEUTSCHE BLÄTTER. Band I, 1943, Heft 1-12. Reprinted by permission of Albert Theile, Unterägeri, Switzerland. Kraus Reprint. Nendeln / Liechtenstein, 1970.

DEUTSCHE BLÄTTER. Band II, 1944, Heft 1-10. Reprinted by permission of Albert Theile, Unterägeri, Switzerland. Kraus Reprint. Nendeln / Liechtenstein, 1970.

DIE SAMMLUNG. Literarische Monatschrift unter dem Patronat von André Gide, Aldous Huxley, Heinrich Mann. Herausgegeben von Klaus Mann. 1934, I Jahgang. Kraus Reprint. Nendeln / Liechtenstein, 1970.

MANN, Heinrich. Schicksal und Aufgabe. In: Deutsche Blätter, Heft 7, 1944.

SOWELL, Thomas. Os intelectuais e a sociedade. Tradução de Mauricio G. Righi. São Paulo: Realizações Editora, 2011.

SOZIALISTISCHE WARTE. I. Jahrgang, I. Heft. Maio de 1934. 